\title{
Body mass index and lung cancer risk in never smokers: a meta-analysis
}

\author{
Hongjun Zhu ${ }^{1}$ and Shuanglin Zhang ${ }^{2^{*}}$
}

\begin{abstract}
Background: Obesity is found to increase the risk of most cancer types, but reduce lung cancer risk in many studies. However, the association between obesity and lung cancer is still controversial, mainly owing to the confounding effect of smoking.

Methods: Eligible studies were identified from electric databases to July 1, 2017. Relevant data were extracted and pooled using random-effects models; dose-response and subgroup analyses were also performed.

Results: Twenty-nine studies with more than 10,000 lung cancer cases in15 million never smokers were included. Compared with normal weight, the summary relative risk (RR) was $0.77(95 \%$ confidence interval [Cl]: 0.68-0.88, $P<0.01$ ) for excess body weight (body mass index $[\mathrm{BMl}] \geq 25 \mathrm{~kg} / \mathrm{m}^{2}$ ). An inverse linear dose-response relationship was observed between $\mathrm{BMI}$ and lung cancer risk in never smokers, with an RR of $0.89(95 \% \mathrm{Cl}: 0.84-0.95, P<0.01)$ per $5 \mathrm{~kg} / \mathrm{m}^{2}$ increment in BMI. The results remained stable in most subgroup analyses. However, when stratified by sex, a significant inverse association existed in women but not in men. Similar results were found in analyses for other categories of BMI.
\end{abstract}

Conclusion: Our results indicate that higher BMI is associated with lower lung cancer risk in never smokers.

Keywords: Lung cancer, Obesity, Risk factor, Smoking, Meta-analysis

\section{Background}

Obesity is one of the most important risk factors for several major non-communicable diseases, including cardiovascular diseases, diabetes, and cancer, and the widespread prevalence of obesity is becoming a major threat to global public health [1]. Accumulating evidence suggest that excess body weight not only increases the overall cancer incidence but is also associated with worse outcomes in certain types of cancer [2-4].

As one of the most common cancers in both men and women, lung cancer causes more deaths than any other cancer [5]. Curiously, the association between obesity and lung cancer seems to be different from other cancer types, which has been disputed for years [6-9]. Many previous epidemiological studies found that higher body mass index (BMI) was associated with lower overall lung cancer risk, which was further confirmed in several

\footnotetext{
* Correspondence: zhangshuanglinhn@163.com

${ }^{2}$ Department of Thoracic and Cardiovascular Surgery, the First Affiliated Hospital of Henan University, No. 357 Ximen Street, Kaifeng City 475000, Henan Province, China

Full list of author information is available at the end of the article
}

meta-analyses [10-12] However, the results were always explained by the confounding effect of smoking, which was also associated with lower BMI [7]. Preclinical weight loss and socioeconomic status were also considered to be involved in the association $[3,13]$. Hence, the true relationship between obesity and lung cancer risk remains to be clarified, and interpretation of data in only never smokers might be the best approach to reveal the real picture. Interestingly, several recent studies also reported that higher BMI was associated with better survival in patients with non-small cell lung cancer [14-16].

Lung cancer in never-smokers accounts for approximately $10-15 \%$ of all lung cancer patients and causes more than 15,000 deaths annually [17]. Concerning the association between obesity and lung cancer risk in never smokers, inconsistent results were also reported. In fact, subgroup analyses in previous meta-analyses have reported pooled results for the association. In the first meta-analysis performed by Yang Y, et al., found an significant inverse association between excess weight and lung cancer incidence in non-smokers based on 11

(c) The Author(s). 2018 Open Access This article is distributed under the terms of the Creative Commons Attribution 4.0 International License (http://creativecommons.org/licenses/by/4.0/), which permits unrestricted use, distribution, and 
studies, while the association become insignificant for obesity and overweight categories [11]. Then Duan, et, al. also reported an attenuated linear dose-response association between BMI and lung cancer risk (including both incidence and mortality) in non-smokers, without statistical significance [12]. In the meta-analysis for lung cancer mortality by Shen N, et, al. in 2017, only 2 studies was included in subgroup analysis for never smokers, and the result was 0.95 (95\%CI: 0.88-1.02) [10]. However, the results from the above three meta-analyses were sub-group analyses and based on only a small number of original studies included. To clarify the intrinsic association between obesity and the risk of lung cancer, and avoid the influence of confounding factors, we carried out an updated meta-analysis between body mass index and lung cancer risk in only never smokers, with a more complete literature search, which included both incidence and mortality to increase the sample size and statistical power.

\section{Methods}

\section{Study selection}

We searched the PubMed database to find relevant studies from January 1, 1966, to July 1, 2017.The following key words were used: obesity, overweight, body mass index, body size, leanness, or anthropometric in combination with lung cancer, lung carcinoma, or lung neoplasm. Our literature search was restricted to the full-text publications, and no language restriction was applied. The reference lists of identified articles and other similar meta-analyses were also checked to find additional studies.

\section{Eligibility criteria}

Two independent investigators reviewed all the records and included studies that met the following criteria: 1) study population was never (or non-) smokers, current and former (past or ex-) smokers were not considered in this study, never smokers are defined as those who have not smoked greater than 100 cigarettes in their lifetimes and do not currently smoke; 2) the exposure of interest was BMI $\left(\mathrm{kg} / \mathrm{m}^{2}\right)$, including the categories of obesity, overweight, underweight or excess weight; 3) relative risk (RR) estimates (or hazard ratios or odds ratios) and 95\% confidence intervals (CIs) for never smokers were reported or could be calculated from the data. 4) the outcome was the incidence or mortality of lung cancer; 5) observational studies with a cohort or case-control design. When duplicated studies were reported from the same population, the ones with the longest follow-up were included.

\section{Data extraction and quality assessment}

For each study, the following data were extracted: the first author's name, publication date, country, design, study population, BMI measurement, cancer ascertainment, sex, BMI categories with estimated midpoints, cases and participants per category, RRs with $95 \% \mathrm{CIs}$, and adjusted variables. RRs adjusted for the largest number of confounding variables were adopted. Quality of original studies was assessed by the Newcastle-Ottawa scale [18], which was widely used in observational studies, with a final score $\geq 7$ considered as high quality.

\section{Statistical methods}

Obesity and overweight were defined as BMI $\geq 30$ and $25-29.99 \mathrm{~kg} / \mathrm{m}^{2}$, in accordance with the definitions by of the World Health Organization, whereas excess weight combines the two categories. Normal weight was defined as $18.5-24.99 \mathrm{~kg} / \mathrm{m}^{2}$, which was considered as the reference level. When the RRs with $95 \%$ Cis were reported by different BMI categories, the estimates for alternative comparisons were converted using the methods by Hamling et al. [19]. A fixed-effects model was employed to pool the results separated by sex. For some studies, we extracted the RR estimates from the figures presented in the manuscripts, using the software Engauge Digitizer version 2.11 (free software downloaded from http://sourceforge.net). A random-effects model was used to pool the individual RRs, considering the heterogeneity among studies, which was evaluated by the $Q$ and $I^{2}$ statistics [20].

Only studies that reported RRs with 95\% CIs for at least 3categories were included into the dose-response analysis using the method proposed by Greenland [21] and Orsiniet al. [22]. For each BMI category, the average between the lower and upper boundary was assigned to the corresponding RR. When the extreme category was open-ended, the boundary was assumed to be the same amplitude as adjacent categories. RR trend estimates with $95 \%$ CIs in each study were calculated per $5 \mathrm{~kg} /$ $\mathrm{m}^{2}$ increment in BMI and pooled together using a random-effects model. To compute the study-specific slope from the correlated $\log \mathrm{RR}$ estimates across BMI levels, a two-stage generalized least-squares method with fractional-polynomial regression models was employed [22]. To test for nonlinearity, a likelihood ratio test was used to investigate the difference between nonlinear and linear models.

We also carried out subgroup analyses stratified by potential confounding factors, including study design, outcome, sex, diagnosis method, ethnicity, and quality. Meta-regression analyses were performed to explore the sources of heterogeneity. To evaluate the stability of the results, sensitivity analysis was employed to examine the change of pooled results after removing one study each time. Publication bias was assessed by funnel plot and Egger's test, $p<0.10$ was regarded as statistically significant, and the trim-and-fill method was used to adjust for potential 
bias. All statistical analyses were done with the STATA version 12.0 software (Stata Corporation, College Station, TX).

\section{Results}

\section{Literature search and study characteristics}

In total, 3937 articles were identified from the databases, and after removing the ineligible studies, 29 studies were included in the meta-analysis, including 21 cohort studies and 8 case-control studies (Fig. 1). Among these studies, 24 reported the RRs for lung cancer incidence and 5 provided mortality data. Twelve were from America, 7 from Europe, 10 from Asia. Two studies in Chinese were included in our study [23, 24]. 2studies were excluded because of multiple reports of the same population [7, 25].

In general, the quality scores ranged from 4 to 9 with an average of 7 points (7.3 for cohort studies and 6.2 for case-control studies). Among all studies, 21 were considered as high quality ( $\geq 7$ points). The most common confounders adjusted in original studies included age, sex, alcohol consumption, vegetable/fruit intake, and physical activity; however, few studies were controlled for total calorie intake, other chronic diseases, concomitant medication, or environmental status. The baseline characteristics of all studies are shown in Additional file 1: Table S1 and the quality scores are listed in Additional file 2: Table S2 and Additional file 3: Table S3.

\section{Overall analyses}

Overall analyses showed that there was an inverse association between BMI and lung cancer risk in never smokers. Eighteen and 15 studies reported the data for obesity and overweight categories, respectively. After pooling all results, RRs were $0.78(95 \%$ CI: $0.65-0.94, P$ $=0.01)$ and $0.76(95 \%$ CI: $0.65-0.87, P<0.01)$ compared with the normal category. Combined analysis of 23 studies showed that the RR was 0.77 (95\% CI: $0.68-0.88, P<$ 0.01 ) for the excess weight category (Fig. 2). Substantial heterogeneity was observed among the included studies, $I^{2}$ was $54.30,50.60$, and $62.40 \%$ for obesity, overweight, and excess weight categories, respectively.

Subgroup analyses suggested that RRs did not differ significantly by design, outcome, cancer ascertainment, BMI assessment, quality, or whether important confounders were adjusted for in original studies, although some results were statistically negative, mainly owing to the small number of studies included. When stratified by sex, some differences were observed; the results for women were consistently significant for all categories, whereas no positive associations were found for men (Table 1). To avoid the disturbance by preclinical weight loss caused by early lung cancer itself, studies were ruled out in which BMI was measured $<5$ years before the diagnosis of lung cancer [12, 23, 25-28], and the pooled analysis of remaining studies gave an RR of 0.79 (95\% CI: $0.70-0.91, P<0.01)$ for the excess weight category.

\section{Dose-response analyses}

Finally, 28 studies were included in the dose-response analysis; the summary RR was 0.89 (95\% CI: $0.84-0.95$, $P<0.01$ ) per $5 \mathrm{~kg} / \mathrm{m}^{2}$ increase in BMI, with a high

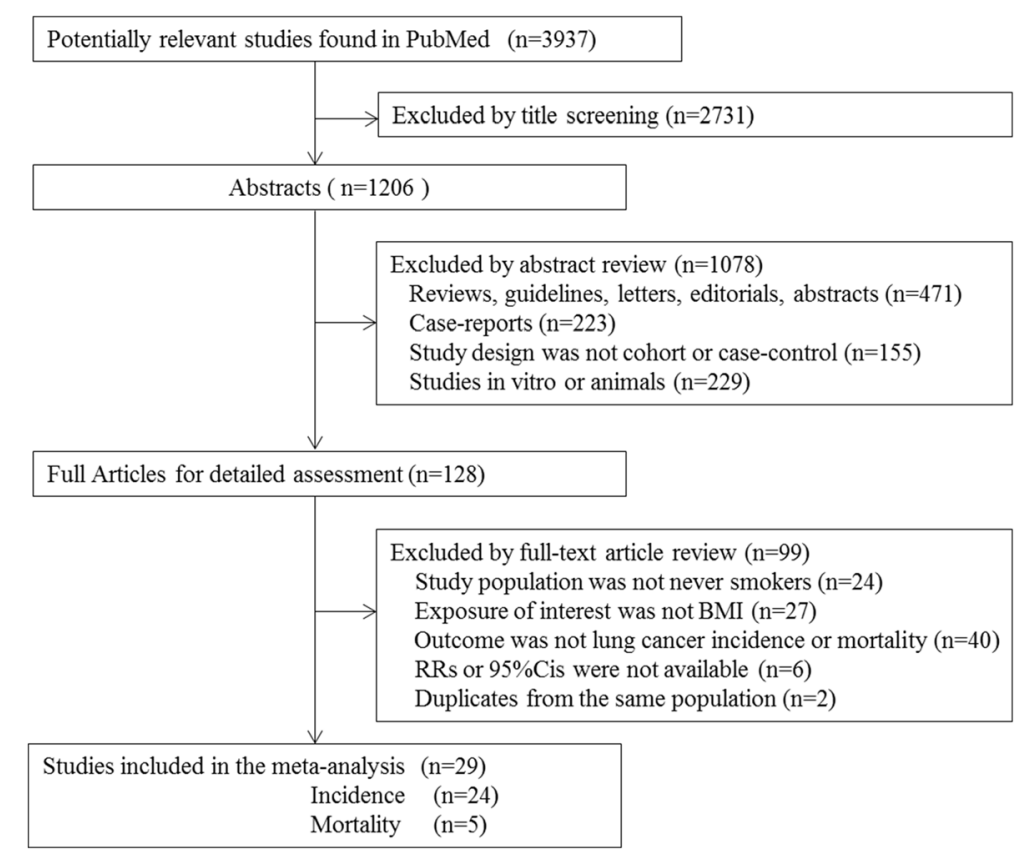

Fig. 1 Flow chart of literature search 


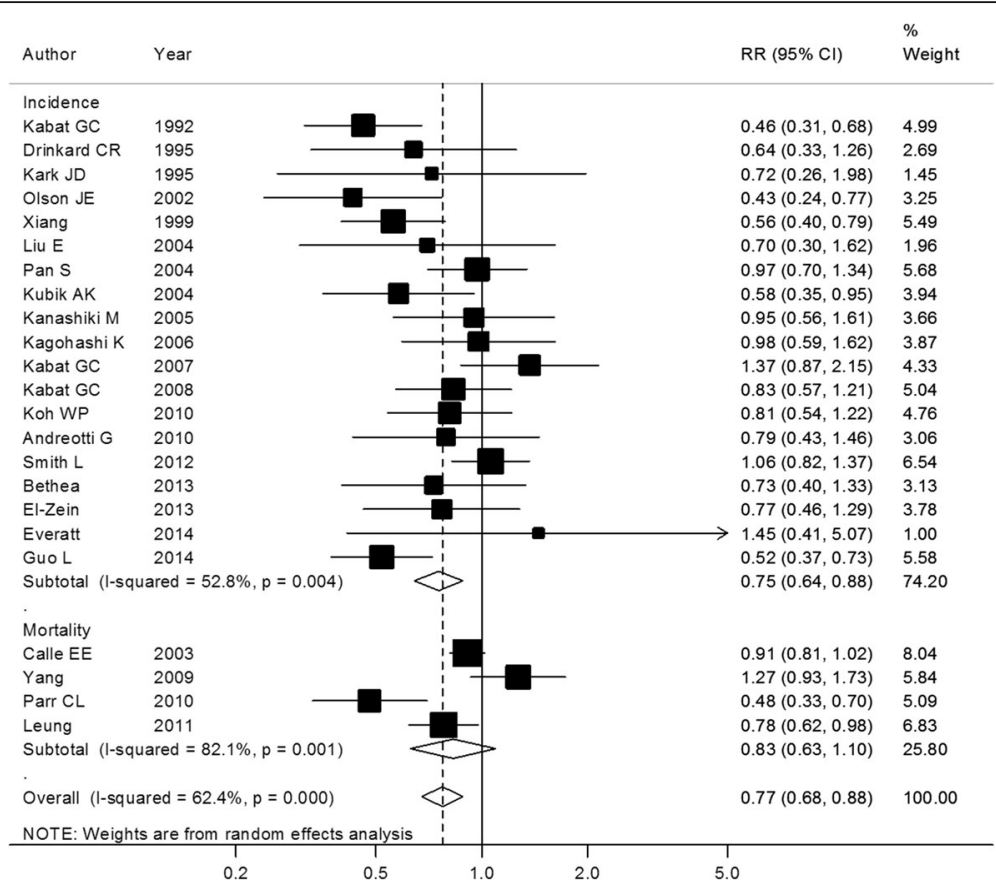

Fig. 2 Excess weight and lung cancer risk in never smokers. Box sizes reflect the weights of studies included in the meta-analysis, horizontal lines are the $95 \% \mathrm{Cls}$, and the summary RR is represented by the diamond. RR: relative risk, Cl: confidence interval

heterogeneity $\left(I^{2}=86.44 \%\right) \quad$ (Fig. 3). The RRs were 0.89(95\% CI: $0.82-0.96, P<0.01)$ for cohort studies and $0.90(95 \% \mathrm{CI}: 0.79-1.03, P=0.13)$ for case-control studies (Table 1). No significant differences were observed in subgroup analyses stratified by most confounders. When stratified by sex, the RRs were 0.89(95\% CI: $0.81-0.97, P<0.01)$ and $0.96(95 \% \mathrm{CI}$ : $0.83-1.11, P=0.60)$ for women and men, respectively (Fig. 4). The combined analysis of studies in which BMI was measure $>5$ years before diagnosis gave an RR of 0.90 (95\% CI: $0.84-0.96, P<0.01)$ per $5 \mathrm{~kg} / \mathrm{m} 2$ increase in BMI.

No evidence of a nonlinear relationship between BMI and lung cancer risk in never smokers was found ( $p$ for nonlinearity $=0.18$ ), and an inverse linear trend was fitted in a random-effects meta-regression model (Fig. 5). Compared with BMI of $20 \mathrm{~kg} / \mathrm{m}^{2}$, the RRs were 1.17(95\% CI: $1.02-1.34, P=0.02)$, 0.87(95\% CI: $0.83-$ 0.92, $P<0.01$ ), 0.81 (95\% CI: $0.76-0.87, P<0.01$ ), and 0.80 (95\% CI: $0.68-0.94, P<0.01$ ) for BMI of $15,25,30$, and $35 \mathrm{~kg} / \mathrm{m}^{2}$, respectively. When stratified by sex, the inverse linear trend was still present for women but disappeared for men.

Meta-regression, sensitivity analyses, and publication bias As described above, substantial heterogeneity was observed across studies, but meta-regression analyses showed that most of the confounders including BMI assessment, ethnicity, design, quality, outcome, and diagnosis method were not significantly associated with the heterogeneity. After excluding the 2 outlier studies by Kabat, et, al. [29] and Kondo, et, al. [30], the heterogeneity was reduced to some extent, but the results were unchanged. The results were still robust after removing one specific study each time in the sensitivity analysis. A slight publication bias was found in the analysis of the obesity category ( $p=0.046$ by Egger's test, $p=0.20$ by Begg's test), but no studies were needed to be filled with the use of trim and fill method, suggesting that the influence could be negligible. In fact, the bias might be caused by insufficient data reported in original studies on the category of obesity, since in other category analyses, the funnel plots seemed to be symmetrical, and no significant publication biases were found.

\section{Discussion}

In the pooled analysis of 29 observational studies, involving more than 10,000 lung cancer cases in 15 million never smokers, the results suggested that higher BMI was associated with lower lung cancer risk, especially in women. In contrast with previous meta-analyses, our study includes the largest sample up to now, and the results were stable both in the subgroup and dose-response analyses.

Previous studies reported that obesity was associated with a lower risk of certain cancer types, particularly smoking related-cancers $[2,11,12,31]$. However, the results were less convincing owing to the small sample size 
Table 1 Subgroup analyses for the association between BMI and lung cancer risk in never smokers

\begin{tabular}{|c|c|c|c|c|c|c|c|c|}
\hline \multirow[t]{2}{*}{ Categories } & \multirow[t]{2}{*}{ Subgroups } & \multirow{2}{*}{$\begin{array}{l}\text { Number of } \\
\text { studies }\end{array}$} & \multirow[t]{2}{*}{ RR $(95 \% \mathrm{Cl})$} & \multirow[t]{2}{*}{$P$ value } & \multicolumn{3}{|c|}{ Heterogeneity } & \multirow[t]{2}{*}{ P-interaction } \\
\hline & & & & & chi-squared & $P^{2}$ & P-heterogeneity & \\
\hline Obesity & & 18 & $0.78(0.65-0.94)$ & 0.01 & 37.23 & $54.30 \%$ & $<0.01$ & \\
\hline \multirow[t]{2}{*}{ Design } & Cohort & 14 & $0.74(0.60-0.91)$ & $<0.01$ & 27.83 & $53.30 \%$ & 0.01 & 0.32 \\
\hline & Case-control & 4 & $0.97(0.58-1.62)$ & 0.90 & 8.75 & $65.70 \%$ & 0.03 & \\
\hline \multirow[t]{2}{*}{ Outcome } & Incidence & 15 & $0.79(0.63-0.99)$ & 0.04 & 30.83 & $54.60 \%$ & $<0.01$ & 0.74 \\
\hline & Mortality & 3 & $0.71(0.45-1.12)$ & 0.14 & 6.40 & $68.70 \%$ & 0.04 & \\
\hline \multirow[t]{2}{*}{ Gender } & Male & 5 & $0.69(0.41-1.15)$ & 0.16 & 16.58 & $69.80 \%$ & $<0.01$ & 0.81 \\
\hline & Female & 8 & $0.86(0.72-1.02)$ & 0.08 & 7.49 & $19.90 \%$ & 0.28 & \\
\hline \multirow[t]{2}{*}{ Ethnicity } & Non-Asian & 13 & $0.82(0.64-1.04)$ & 0.10 & 27.92 & $57.00 \%$ & $<0.01$ & 0.51 \\
\hline & Asian & 5 & $0.70(0.54-0.91)$ & $<0.01$ & 5.56 & $28.00 \%$ & 0.24 & \\
\hline \multirow[t]{2}{*}{ Quality } & High & 12 & $0.76(0.61-0.94)$ & 0.01 & 27.5 & $60.00 \%$ & 0.004 & 0.72 \\
\hline & Low & 6 & $0.84(0.55-1.29)$ & 0.43 & 9.72 & $48.60 \%$ & 0.08 & \\
\hline \multirow[t]{2}{*}{ Diagnosis } & Registry & 10 & $0.77(0.59-1.00)$ & 0.05 & 22.28 & $59.60 \%$ & $<0.01$ & 0.89 \\
\hline & Pathology & 8 & $0.79(0.59-1.06)$ & 0.11 & 14.16 & $50.60 \%$ & 0.05 & \\
\hline \multicolumn{9}{|c|}{ Adjustment for confounders } \\
\hline \multirow[t]{2}{*}{ Alcohol intake } & Yes & 11 & $0.83(0.68-1.02)$ & 0.07 & 18.98 & $47.30 \%$ & 0.04 & 0.49 \\
\hline & No & 7 & $0.68(0.45-1.04)$ & 0.07 & 16.25 & $63.10 \%$ & 0.01 & \\
\hline \multirow[t]{2}{*}{ Vegetable/fruit intake } & Yes & 6 & $0.81(0.58-1.13)$ & 0.22 & 12.80 & $60.90 \%$ & 0.02 & 0.80 \\
\hline & No & 12 & $0.76(0.59-0.97)$ & 0.03 & 23.41 & $53.00 \%$ & 0.02 & \\
\hline \multirow[t]{2}{*}{ Physical activity } & Yes & 9 & $0.91(0.75-1.11)$ & 0.34 & 12.18 & $34.30 \%$ & 0.14 & 0.19 \\
\hline & No & 9 & $0.67(0.49-0.93)$ & 0.02 & 18.15 & $55.90 \%$ & 0.02 & \\
\hline \multirow[t]{2}{*}{ Medical history ${ }^{a}$} & Yes & 3 & $0.78(0.58-0.95)$ & 0.24 & 35.80 & $60.90 \%$ & $<0.01$ & 0.61 \\
\hline & No & 15 & $0.90(0.76-1.07)$ & 0.02 & 0.78 & $0.00 \%$ & 0.68 & \\
\hline Overweight & & 15 & $0.76(0.65-0.87)$ & $<0.01$ & 28.37 & $50.60 \%$ & 0.01 & \\
\hline \multirow[t]{2}{*}{ Design } & Cohort & 12 & $0.74(0.62-0.88)$ & $<0.01$ & 27.30 & $59.70 \%$ & $<0.01$ & 0.78 \\
\hline & Case-control & 3 & $0.80(0.63-1.02)$ & 0.08 & 1.03 & $0.00 \%$ & 0.60 & \\
\hline \multirow[t]{2}{*}{ Outcome } & Incidence & 12 & $0.76(0.64-0.90)$ & $<0.01$ & 16.92 & $35.00 \%$ & 0.11 & 0.93 \\
\hline & Mortality & 3 & $0.73(0.53-1.01)$ & 0.06 & 10.51 & $81.00 \%$ & $<0.01$ & \\
\hline \multirow[t]{2}{*}{ Gender } & Male & 5 & $0.92(0.62-1.36)$ & 0.68 & 14.38 & $72.20 \%$ & $<0.01$ & 0.44 \\
\hline & Female & 8 & $0.82(0.72-0.93)$ & $<0.01$ & 6.52 & $0.00 \%$ & 0.48 & \\
\hline \multirow[t]{2}{*}{ Ethnicity } & Non-Asian & 11 & $0.87(0.78-0.97)$ & $<0.01$ & 10.34 & $3.30 \%$ & 0.41 & 0.09 \\
\hline & Asian & 4 & $0.61(0.44-0.86)$ & $<0.01$ & 10.87 & $72.40 \%$ & 0.01 & \\
\hline \multirow[t]{2}{*}{ Quality } & High & 10 & $0.85(0.77-0.94)$ & $<0.01$ & 9.47 & $4.90 \%$ & 0.40 & 0.32 \\
\hline & Low & 5 & $0.70(0.46-1.06)$ & 0.09 & 13.76 & $70.90 \%$ & $<0.01$ & \\
\hline Diagnosis & Registry & 8 & $0.82(0.68-0.98)$ & 0.03 & 14.38 & $51.30 \%$ & 0.04 & 0.25 \\
\hline & Pathology & 7 & $0.68(0.55-0.84)$ & $<0.01$ & 8.74 & $31.40 \%$ & 0.19 & \\
\hline Adjustment for confound & & & & & & & & \\
\hline Alcohol intake & Yes & 11 & $0.79(0.68-0.92)$ & $<0.01$ & 18.32 & $45.40 \%$ & 0.05 & 0.37 \\
\hline & No & 4 & $0.67(0.46-0.97)$ & 0.03 & 6.36 & $52.80 \%$ & 0.10 & \\
\hline Vegetable/fruit intake & Yes & 5 & 0.89(0.79-0.99) & 0.03 & 1.46 & $0.00 \%$ & 0.83 & 0.15 \\
\hline & No & 10 & $0.68(0.54-0.85)$ & $<0.01$ & 22.26 & $50.60 \%$ & $<0.01$ & \\
\hline Physical activity & Yes & 9 & $0.87(0.77-0.97)$ & 0.02 & 8.86 & $9.70 \%$ & 0.35 & 0.14 \\
\hline & No & 6 & $0.66(0.49-0.88)$ & $<0.01$ & 12.85 & $61.10 \%$ & 0.02 & \\
\hline
\end{tabular}


Table 1 Subgroup analyses for the association between BMI and lung cancer risk in never smokers (Continued)

\begin{tabular}{|c|c|c|c|c|c|c|c|c|}
\hline \multirow[t]{2}{*}{ Categories } & \multirow[t]{2}{*}{ Subgroups } & \multirow{2}{*}{$\begin{array}{l}\text { Number of } \\
\text { studies }\end{array}$} & \multirow[t]{2}{*}{ RR $(95 \% \mathrm{Cl})$} & \multirow[t]{2}{*}{$P$ value } & \multicolumn{3}{|c|}{ Heterogeneity } & \multirow[t]{2}{*}{ P-interaction } \\
\hline & & & & & chi-squared & $P^{2}$ & P-heterogeneity & \\
\hline \multirow[t]{2}{*}{ Medical history $^{a}$} & Yes & 3 & $0.89(0.79-1.00)$ & 0.05 & 24.35 & $0.00 \%$ & 0.66 & \multirow[t]{2}{*}{0.42} \\
\hline & No & 12 & $0.72(0.60-0.87)$ & $<0.01$ & 0.84 & $50.60 \%$ & 0.01 & \\
\hline Excess weight & & 23 & $0.77(0.68-0.88)$ & $<0.01$ & 58.46 & $62.40 \%$ & $<0.01$ & \\
\hline \multirow[t]{2}{*}{ Design } & Cohort & 16 & $0.80(0.69-0.94)$ & $<0.01$ & 40.07 & $62.60 \%$ & $<0.01$ & \multirow[t]{2}{*}{0.47} \\
\hline & Case-control & 7 & $0.71(0.56-0.91)$ & $<0.01$ & 13.78 & $56.50 \%$ & 0.03 & \\
\hline \multirow[t]{2}{*}{ Outcome } & Incidence & 19 & $0.75(0.64-0.88)$ & $<0.01$ & 38.12 & $52.80 \%$ & $<0.01$ & \multirow[t]{2}{*}{0.60} \\
\hline & Mortality & 4 & $0.83(0.63-1.10)$ & 0.19 & 16.73 & $82.10 \%$ & $<0.01$ & \\
\hline \multirow[t]{2}{*}{ Gender } & Male & 8 & $0.88(0.70-1.11)$ & 0.29 & 17.94 & $55.40 \%$ & 0.02 & \multirow[t]{2}{*}{0.85} \\
\hline & Female & 12 & $0.75(0.62-0.91)$ & $<0.01$ & 28.89 & $61.90 \%$ & $<0.01$ & \\
\hline \multirow[t]{2}{*}{ Ethnicity } & Non-Asian & 14 & $0.80(0.68-0.95)$ & $<0.01$ & 28.25 & $54.00 \%$ & $<0.01$ & \multirow[t]{2}{*}{0.66} \\
\hline & Asian & 9 & $0.74(0.59-0.94)$ & 0.01 & 26.05 & $69.30 \%$ & $<0.01$ & \\
\hline \multirow[t]{2}{*}{ Quality } & High & 16 & $0.83(0.73-0.95)$ & $<0.01$ & 30.06 & $50.10 \%$ & 0.01 & \multirow[t]{2}{*}{0.18} \\
\hline & Low & 7 & $0.68(0.50-0.90)$ & $<0.01$ & 17.7 & $66.10 \%$ & $<0.01$ & \\
\hline \multirow[t]{2}{*}{ Diagnosis } & Registry & 11 & $0.88(0.75-1.05)$ & 0.15 & 24.27 & $58.80 \%$ & $<0.01$ & \multirow[t]{2}{*}{0.06} \\
\hline & Pathology & 12 & $0.68(0.57-0.81)$ & $<0.01$ & 19.97 & $44.90 \%$ & 0.05 & \\
\hline \multicolumn{9}{|l|}{ Adjustment for confounders } \\
\hline \multirow[t]{2}{*}{ Alcohol intake } & Yes & 12 & $0.83(0.71-0.97)$ & 0.02 & 26.74 & $58.90 \%$ & 0.01 & 0.31 \\
\hline & No & 11 & $0.71(0.57-0.89)$ & $<0.01$ & 22.73 & $56.00 \%$ & $<0.01$ & \\
\hline Vegetable/fruit intake & Yes & 7 & $0.85(0.69-1.05)$ & 0.13 & 17.29 & $57.10 \%$ & $<0.01$ & 0.37 \\
\hline & No & 16 & $0.73(0.62-0.87)$ & $<0.01$ & 34.93 & $65.30 \%$ & $<0.01$ & \\
\hline Physical activity & Yes & 9 & $0.87(0.77-0.99)$ & 0.04 & 10.14 & $21.10 \%$ & 0.26 & 0.52 \\
\hline & No & 14 & $0.75(0.61-0.92)$ & $<0.01$ & 41.15 & $68.40 \%$ & $<0.01$ & \\
\hline Medical history ${ }^{a}$ & Yes & 7 & $0.84(0.68-1.04)$ & 0.11 & 13.32 & $55.00 \%$ & 0.04 & 0.52 \\
\hline & No & 16 & $0.75(0.63-0.89)$ & $<0.01$ & 40.57 & $63.00 \%$ & $<0.01$ & \\
\hline BMI increase per $5 \mathrm{Kg} / \mathrm{m}^{2}$ & & 28 & $0.89(0.84-0.95)$ & $<0.01$ & 86.44 & $68.80 \%$ & $<0.01$ & \\
\hline Design & Cohort & 20 & $0.89(0.82-0.96)$ & $<0.01$ & 58.12 & $67.30 \%$ & $<0.01$ & 0.88 \\
\hline & Case-control & 8 & $0.90(0.79-1.03)$ & 0.13 & 24.77 & $71.70 \%$ & 0.01 & \\
\hline Outcome & Incidence & 23 & $0.89(0.83-0.96)$ & $<0.01$ & 65.3 & $66.30 \%$ & $<0.01$ & 0.98 \\
\hline & Mortality & 5 & $0.89(0.76-1.04)$ & 0.16 & 20.98 & $80.90 \%$ & $<0.01$ & \\
\hline Gender & Male & 12 & $0.96(0.83-1.11)$ & 0.60 & 28.43 & $61.30 \%$ & $<0.01$ & 0.42 \\
\hline & Female & 13 & $0.89(0.81-0.97)$ & $<0.01$ & 34.74 & $65.50 \%$ & $<0.01$ & \\
\hline Ethnicity & Non-Asian & 18 & $0.91(0.84-0.98)$ & 0.01 & 47.23 & $64.00 \%$ & $<0.01$ & 0.66 \\
\hline & Asian & 10 & $0.88(0.78-0.98)$ & 0.03 & 33.12 & $72.80 \%$ & $<0.01$ & \\
\hline Quality & High & 20 & $0.91(0.86-0.98)$ & $<0.01$ & 51.74 & $63.30 \%$ & $<0.01$ & 0.39 \\
\hline & Low & 8 & $0.85(0.72-1.00)$ & 0.05 & 26.41 & $73.50 \%$ & $<0.01$ & \\
\hline Diagnosis & Registry & 15 & $0.93(0.86-1.00)$ & 0.06 & 42.41 & $67.00 \%$ & $<0.01$ & 0.35 \\
\hline & Pathology & 13 & $0.86(0.78-0.95)$ & $<0.01$ & 32.26 & $62.80 \%$ & $<0.01$ & \\
\hline Adjustment for confound & & & & & & & & \\
\hline Alcohol intake & Yes & 15 & $0.89(0.83-0.95)$ & $<0.01$ & 36.97 & $62.10 \%$ & $<0.01$ & 0.60 \\
\hline & No & 13 & $0.92(0.79-1.07)$ & 0.28 & 48.42 & $75.20 \%$ & $<0.01$ & \\
\hline Vegetable/fruit intake & Yes & 7 & $0.93(0.84-1.02)$ & 0.13 & 12.57 & $52.3 \%$ & 0.05 & 0.77 \\
\hline & No & 21 & $0.89(0.82-0.96)$ & $<0.01$ & 72.90 & $72.6 \%$ & $<0.01$ & \\
\hline
\end{tabular}


Table 1 Subgroup analyses for the association between BMI and lung cancer risk in never smokers (Continued)

\begin{tabular}{|c|c|c|c|c|c|c|c|c|}
\hline \multirow[t]{2}{*}{ Categories } & \multirow[t]{2}{*}{ Subgroups } & \multirow{2}{*}{$\begin{array}{l}\text { Number of } \\
\text { studies }\end{array}$} & \multirow[t]{2}{*}{ RR $(95 \%$ Cl) } & \multirow[t]{2}{*}{$P$ value } & \multicolumn{3}{|c|}{ Heterogeneity } & \multirow[t]{2}{*}{ P-interactio } \\
\hline & & & & & chi-squared & $P^{2}$ & P-heterogeneity & \\
\hline \multirow[t]{2}{*}{ Physical activity } & Yes & 10 & $0.92(0.86-0.98)$ & $<0.01$ & 11.33 & $20.60 \%$ & 0.25 & 0.96 \\
\hline & No & 18 & $0.90(0.81-0.99)$ & $<0.01$ & 86.44 & $77.3 \%$ & $<0.01$ & \\
\hline \multirow[t]{2}{*}{ Medical history $^{a}$} & Yes & 11 & $0.90(0.83-0.97)$ & $<0.01$ & 29.05 & $65.60 \%$ & $<0.01$ & 0.84 \\
\hline & No & 17 & $0.88(0.80-0.98)$ & 0.02 & 56.45 & $71.70 \%$ & $<0.01$ & \\
\hline
\end{tabular}

Note: In the subgroup analyses, ${ }^{a}$ medical history included history of chronic lung disease, history of family lung cancer, diabetes status, and hormone treatment. Other confounders such as total energy intake, environmental status and concomitant medication (use of aspirin and metformin) were not common in original studies; thus, subgroup analyses stratified by them were not performed

and other confounding factors, especially smoking. Meta-analysis is a quantitative approach that combines the results from multiple studies and increases the statistical power to resolve uncertainty in single studies for a more reliable conclusion. Thus, our study has a number of advantages. We included all the eligible epidemiological studies investigating the association between BMI and lung cancer risk in never smokers and redefined comparable exposure categories, which allowed for better control of confounders, subgroup analyses, and further dose-response analyses.

As we mentioned previously, several hypotheses have been put forward to explain the inverse association between lung cancer risk and BMI. As our study was limited to never smokers, the confounding of smoking, one of the most common arguments for the trend, was avoided as much as possible. A second hypothesis is that the lower BMI might reflect preclinical weight loss caused by early lung cancer itself or other related diseases. To solve this doubt, only studies in which BMI was measured 5 or more years before diagnosis were analyzed, and the inverse association remained unchanged. In fact, the participants with previous clinical weight loss were excluded at recruitment in most studies. It was also speculated that socioeconomic factors might be relevant to the inverse association, such as indoor air pollution in developing countries; however, our results indicated that the inverse association was stable across the strata of ethnicity.

Interestedly, we found a sex difference in the association between BMI and lung cancer risk, although p-interaction for sex is not statistically significant. Previous studies reported paradoxical results concerning the

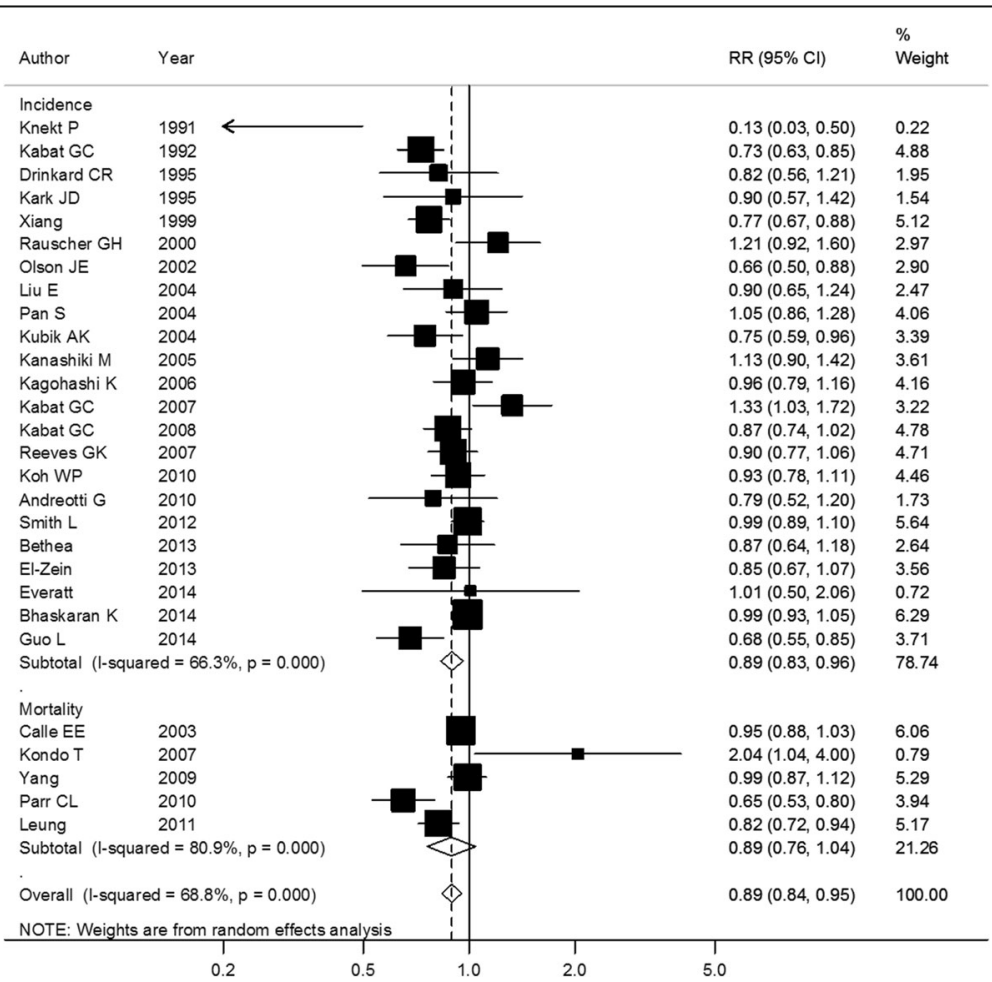

Fig. 3 Association between BMI and lung cancer risk per $5 \mathrm{~kg} / \mathrm{m}^{2}$ increase. Box sizes reflect the weights of studies included in the meta-analysis, horizontal lines are the $95 \% \mathrm{Cls}$, and the summary RR is represented by the diamond. BMl: body mass index, RR: relative risk, Cl: confidence interval 


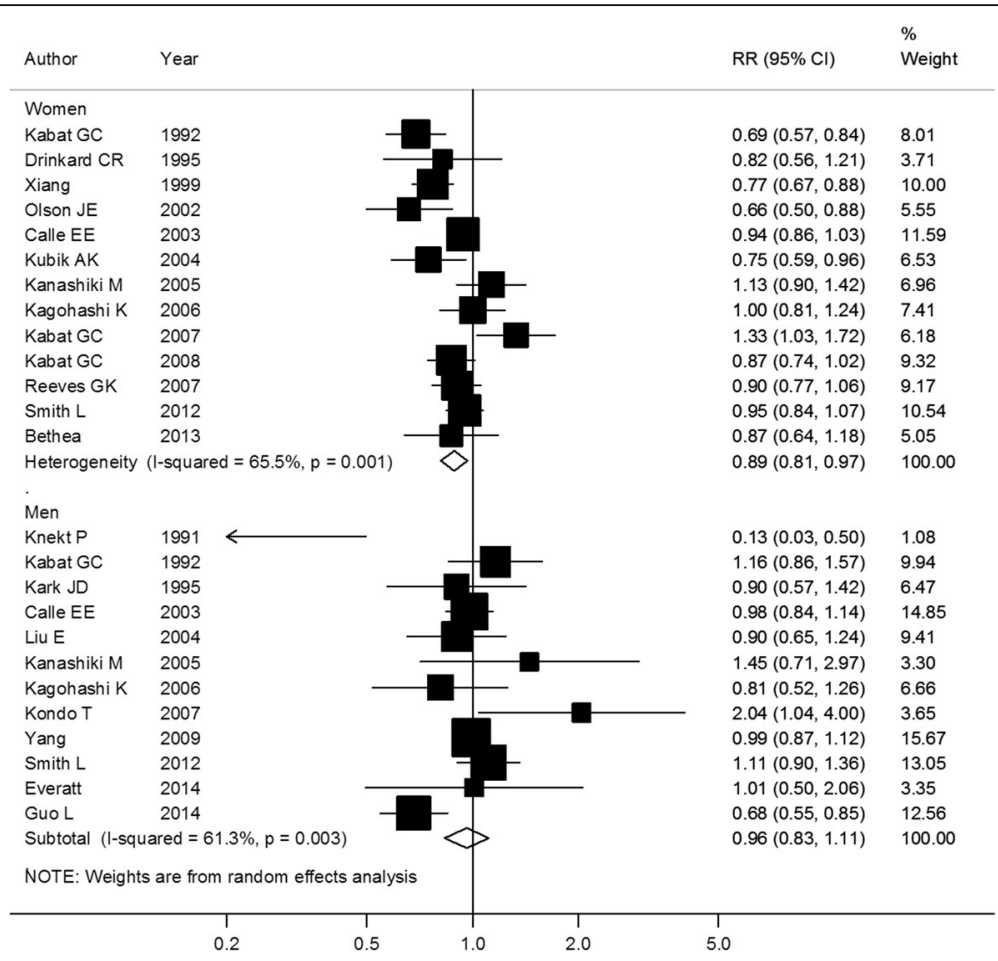

Fig. 4 Association between BMl and lung cancer risk per $5 \mathrm{~kg} / \mathrm{m}^{2}$ increase, stratified by sex. Box sizes reflect the weights of studies included in the meta-analysis, horizontal lines are the $95 \% \mathrm{Cls}$, and the summary RR is represented by the diamond. BMl: body mass index, RR: relative risk, Cl: confidence interval

differences between sexes [11, 12], Smith et al. found that BMI was more strongly related to lower lung cancer risk in women than in men in a large cohort study [26]. The authors speculated that estrogens might play a protective role in lung cancer development [26], which was in accordance with our results. Notably, since more men than women are smokers, the results for the men in our

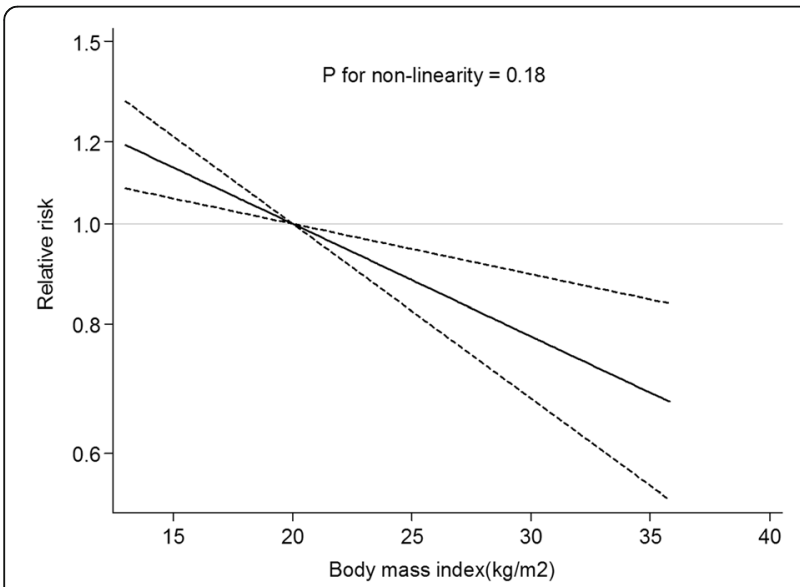

Fig. 5 Dose-response analysis for body mass index and lung cancer risk in never smokers. The solid line represents the trend between BMI and lung cancer risk, and the dashed lines represent the 95\% confidence intervals. The displayed $p$-values refer to the test for nonlinearity meta-analysis might be influenced by the relatively smaller sample size, more studies are warranted to explore the sex difference.

Not only epidemiological studies revealed the possibility that obesity might lower lung cancer risk, but some biological discoveries also provided useful hints. It has long been noted that lower BMI might increase the susceptibility of DNA to chemical carcinogens in cigarettes [27], and excess weight was associated with decreased chromosome damage [28]. Some studies also suggested that adipose tissue was helpful to keep the memory of $\mathrm{CD}^{+} \mathrm{T}$ cells to maintain normal immune functions [32]. In addition, increased insulin-like growth factor-1 level which might explain the obesity-carcinogenesis connection was found not to be associated with lung cancer [33]. Paradoxically, systemic inflammation, which might increase lung cancer risk [33], is also closely associated with obesity [34]. These studies provide possible direction for more in-depth research in this field to better clarify the obesity paradox in lung cancer development.

The results of our study should be interpreted with caution, as associations found in a meta-analysis of observational studies do not reveal causation. Several other limitations should also be considered. First, concerning the outcomes of interest, both the incidence and mortality of lung cancer were included. It is reasonable to do 
this since lung cancer is relatively rare in the overall population, and previous studies reported that the incidence and mortality of lung cancer almost coincided with each other [35]. Second, inherent limitations in original studies were inevitable, especially for the case-control studies, which were prone to recall and selection bias, inconsistencies in baseline characteristics of original studies including different study populations, pathology type, ethnicity, ages, and duration all contributed to heterogeneity across studies. However, no individual confounder significantly influenced the heterogeneity by meta-regression, and subgroup analyses by these confounders were almost the same, indicating the stability of our results. Third, in some studies, BMI was calculated by self-reported weight and height, and different exposure ranges were adopted across different studies, which might lead to some incomparability of results. To solve the problem, we conducted different category comparisons and dose-response analyses as well as subgroup analyses stratified by BMI assessment, and the results were consistently stable to support our conclusion, which was further validated by the sensitivity analyses In addition, although no significant differences were found between studies whether they were adjusted for common confounders or not, insufficient adjustment of other potential confounders, including secondhand smoking, occupational exposure to lung carcinogens (e.g., radon), concomitant medication (e.g., using of aspirin and metformin) might distort our results, and we also had insufficient data on different histological types of lung cancer for further subgroup analyses. Lastly, only articles in full-text were included in our analysis, abstracts, trial registries were not retrieved, some studies might be missed. However, no significant publication bias was observed except in the analysis of the obesity category, and no studies were required using the "trim and fill" method, suggesting that the influence was slight.

Every sword has two edges. Obesity has been stereotyped as a risk factor for many chronic diseases including most types of cancer, but our study shows that higher BMI is associated with lower lung cancer risk, especially in women. Our results do not suggest increasing body weight to decrease the risk of lung cancer; however, underweight is also inadvisable, and maintaining a proper weight is the best choice. The results of our study are helpful to explain the J-shaped association between BMI and total mortality [1]. Further studies should be focused on the mechanisms underlying the phenomena, and extra efforts are needed to reduce the unfavorable effects of obesity on most cancer types and other chronic diseases.

\section{Conclusions}

In conclusion, the results of our meta-analysis indicate that higher BMI is associated with lower lung cancer risk, especially in women, which alter our common understanding of the relationship between obesity and cancer, although the causal relationship between these two factors cannot be determined from this analysis. Additional studies are required to validate these findings and to better understand the biologic rationale for this observation.

\section{Additional files}

Additional file 1: Table S1. Characteristics of studies included in the meta-analysis of obesity and lung cancer risk in non-smokers. (DOCX 88 $\mathrm{kb})$

Additional file 2: Table S2. Quality scores of the cohort studies included in the meta-analysis, assessed by the Newcastle-Ottawa scale. (DOCX $20 \mathrm{~kb}$ )

Additional file 3: Table S3. Quality scores of the case-control studies included in the meta-analysis, assessed by the Newcastle-Ottawa scale. (DOCX $18 \mathrm{~kb})$

\section{Abbreviations}

BMI: body mass index; Cl: confidence interval; FTO: fat mass- and obesityassociated gene; RR: relative risk

\section{Availability of data and materials}

The datasets supporting the conclusions of this article are included within the article.

\section{Authors' contributions}

$\mathrm{HZ}$ and $\mathrm{SZ}$ conceived and drafted the study; $\mathrm{HZ}$ and $\mathrm{SZ}$ conducted the literature research and collected all data; $\mathrm{HZ}$ and $\mathrm{SZ}$ analyzed and interpreted data; All authors commented on drafts of the paper and approved the final manuscript.

\section{Ethics approval and consent to participate}

This work did not require any written patient consent. The ethics committee of the First Affiliated Hospital of Henan University approved this work.

\section{Competing interests}

The authors declare that they have no competing interests.

\section{Publisher's Note}

Springer Nature remains neutral with regard to jurisdictional claims in published maps and institutional affiliations.

\section{Author details}

${ }^{1}$ Department of thoracic surgery, Shangqiu First People's Hospital, Shangqiu 476100, Henan, China. ${ }^{2}$ Department of Thoracic and Cardiovascular Surgery, the First Affiliated Hospital of Henan University, No. 357 Ximen Street, Kaifeng City 475000, Henan Province, China.

Received: 14 October 2017 Accepted: 21 May 2018

Published online: 05 June 2018

References

1. Whitlock G, Lewington S, Sherliker P, Clarke R, Emberson J, Halsey J, Qizilbash N, Collins R, Peto R. Body-mass index and cause-specific mortality in 900000 adults: collaborative analyses of 57 prospective studies. Lancet. 2009:373(9669):1083-96.

2. Bhaskaran K, Douglas I, Forbes H, dos-Santos-Silva I, Leon DA, Smeeth L. Body-mass index and risk of 22 specific cancers: a population-based cohort study of 5.24 million UK adults. Lancet. 2014;384(9945):755-65. 
3. Parr CL, Batty GD, Lam TH, Barzi F, Fang X, Ho SC, Jee SH, AnsaryMoghaddam A, Jamrozik K, Ueshima $\mathrm{H}$, et al. Body-mass index and cancer mortality in the Asia-Pacific cohort studies collaboration: pooled analyses of 424,519 participants. Lancet Oncol. 2010;11(8):741-52.

4. Ligibel JA, Alfano CM, Courneya KS, Demark-Wahnefried W, Burger RA, Chlebowski RT, Fabian CJ, Gucalp A, Hershman DL, Hudson MM, et al. American Society of Clinical Oncology position statement on obesity and cancer. J Clin Oncol. 2014;32(31):3568-74.

5. Siegel RL, Miller KD, Jemal A. Cancer statistics, 2016. CA Cancer J Clin. 2016; 66(1):7-30.

6. Knekt P, Heliovaara M, Rissanen A, Aromaa A, Seppanen R, Teppo L, Pukkala E. Leanness and lung-cancer risk. Int J Cancer. 1991;49(2):208-13.

7. Henley SJ, Flanders WD, Manatunga A, Thun MJ. Leanness and lung cancer risk: fact or artifact? Epidemiology. 2002;13(3):268-76.

8. El-Zein M, Parent ME, Rousseau MC. Comments on a recent meta-analysis: obesity and lung cancer. Int J Cancer. 2013;132(8):1962-3.

9. Yang $Y$, Jiao $Y$. Authors' reply to comments on a recent meta-analysis: obesity and lung cancer. Int J Cancer. 2013;132(8):1964-5.

10. Shen N, Fu P, Cui B, Bu C-Y, Bi J-W. Associations between body mass index and the risk of mortality from lung cancer: a dose-response PRISMA-compliant meta-analysis of prospective cohort studies. Med. 2017;96(34):e7721

11. Yang Y, Dong J, Sun K, Zhao L, Zhao F, Wang L, Jiao Y. Obesity and incidence of lung cancer: a meta-analysis. Int J Cancer. 2013;132(5):1162-9.

12. Duan P, Hu C, Quan C, Yi X, Zhou W, Yuan M, Yu T, Kourouma A, Yang K. Body mass index and risk of lung cancer: systematic review and doseresponse meta-analysis. Sci Rep. 2015;5:16938.

13. El-Zein M, Parent ME, Nicolau B, Koushik A, Siemiatycki J, Rousseau MC. Body mass index, lifetime smoking intensity and lung cancer risk. Int J Cancer. 2013;133(7):1721-31.

14. Gupta A, Majumder K, Arora N, Mayo HG, Singh PP, Beg MS, Hughes R, Singh $\mathrm{S}$, Johnson $\mathrm{DH}$. Premorbid body mass index and mortality in patients with lung cancer: a systematic review and meta-analysis. Lung Cancer. 2016; 102:49-59.

15. Zhang $X$, Liu $Y$, Shao H, Zheng X. Obesity paradox in lung Cancer prognosis: evolving biological insights and clinical implications. J Thorac Oncol. 2017; 12(10):1478-88.

16. Lam VK, Bentzen SM, Mohindra P, Nichols EM, Bhooshan N, Vyfhuis M, Scilla KA, Feigenberg SJ, Edelman MJ, Feliciano JL. Obesity is associated with long-term improved survival in definitively treated locally advanced nonsmall cell lung cancer (NSCLC). Lung Cancer. 2017;104:52-7.

17. Gazdar AF, Thun MJ. Lung cancer, smoke exposure, and sex. J Clin Oncol. 2007;25(5):469-71.

18. Gláucia F. Cota, Marcos R. de Sousa, Tatiani Oliveira Fereguetti, Ana Rabello. Efficacy of Anti-Leishmania Therapy in Visceral Leishmaniasis among HIV Infected Patients: A Systematic Review with Indirect Comparison. PLOS Negl Trop Dis. 2013;7(5):e2195.

19. Hamling J, Lee $P$, Weitkunat $R$, Ambuhl M. Facilitating meta-analyses by deriving relative effect and precision estimates for alternative comparisons from a set of estimates presented by exposure level or disease category. Stat Med. 2008;27(7):954-70.

20. Higgins JP, Thompson SG, Deeks JJ, Altman DG. Measuring inconsistency in meta-analyses. BMJ. 2003:327(7414):557-60.

21. Greenland S, Longnecker MP. Methods for trend estimation from summarized dose-response data, with applications to meta-analysis. Am J Epidemiol. 1992;135(11):1301-9.

22. Orsini NBR, Greenland S. Generalized least squares for trend estimation of summarized dose-response data. Stata J. 2009;6(1):17.

23. Xiang Y, Gao Y, Zhong L, Jin F, Sun L, Cheng J, Zhai Y. A case-control study on relationship between body mass index and lung cancer in non-smoking women. Zhonghua Yu Fang Yi Xue Za Zhi. 1999;33(1):9-12.

24. Guo L, Li N, Wang G, Su K, Li F, Yang L, Ren J, Chang S, Chen S, Wu S, et al. Body mass index and cancer incidence:a prospective cohort study in northern China. Zhonghua Liu Xing Bing Xue Za Zhi. 2014;35(3):231-6.

25. Song YM, Sung J, Ha M. Obesity and risk of cancer in postmenopausal Korean women. J Clin Oncol. 2008;26(20):3395-402.

26. Smith L, Brinton LA, Spitz MR, Lam TK, Park Y, Hollenbeck AR, Freedman ND, Gierach GL. Body mass index and risk of lung cancer among never, former, and current smokers. J Natl Cancer Inst. 2012;104(10):778-89.

27. Loft S, Vistisen K, Ewertz M, Tjonneland A, Overvad K, Poulsen HE. Oxidative DNA damage estimated by 8-hydroxydeoxyguanosine excretion in humans: influence of smoking, gender and body mass index. Carcinogenesis. 1992; 13(12):2241-7.

28. Li X, Bai Y, Wang S, Nyamathira SM, Zhang X, Zhang W, Wang T, Deng Q, He M, Wu T, et al. Association of body mass index with chromosome damage levels and lung cancer risk among males. Sci Rep. 2015;5:9458.

29. Kabat GC, Wynder EL. Body mass index and lung cancer risk. Am J Epidemiol. 1992;135(7):769-74

30. Kondo T, Hori Y, Yatsuya H, Tamakoshi K, Toyoshima H, Nishino Y, Seki N, Ito $Y$, Suzuki K, Ozasa K, et al. Lung cancer mortality and body mass index in a Japanese cohort: findings from the Japan collaborative cohort study (JACC study). Cancer Causes Control. 2007:18(2):229-34.

31. Radoi L, Paget-Bailly S, Cyr D, Papadopoulos A, Guida F, Tarnaud C, Menvielle G, Schmaus A, Cenee S, Carton M, et al. Body mass index, body mass change, and risk of oral cavity cancer: results of a large populationbased case-control study, the ICARE study. Cancer Causes Control. 2013: 24(7):1437-48.

32. Cui G, Staron MM, Gray SM, Ho PC, Amezquita RA, Wu J, Kaech SM. IL-7induced glycerol transport and TAG synthesis promotes memory CD8+ T cell longevity. Cell. 2015;161(4):750-61.

33. Engels EA. Inflammation in the development of lung cancer: epidemiological evidence. Expert Rev Anticancer Ther. 2008;8(4):605-15.

34. lyengar NM, Gucalp A, Dannenberg AJ, Hudis CA. Obesity and Cancer mechanisms: tumor microenvironment and inflammation. J Clin Oncol. 2016:34(35):4270-6.

35. Reeves GK, Pirie K, Beral V, Green J, Spencer E, Bull D. Cancer incidence and mortality in relation to body mass index in the million women study: cohort study. BMJ. 2007;335(7630):1134.

\section{Ready to submit your research? Choose BMC and benefit from:}

- fast, convenient online submission

- thorough peer review by experienced researchers in your field

- rapid publication on acceptance

- support for research data, including large and complex data types

- gold Open Access which fosters wider collaboration and increased citations

- maximum visibility for your research: over $100 \mathrm{M}$ website views per year

At BMC, research is always in progress.

Learn more biomedcentral.com/submissions 